\title{
National Trends and Outcomes of Myocardial Infarction: Result from National Inpatient Sample 2000 to 2015
}

\author{
Abdulrahman S Museedi, MD* (D), Mouhamed Nashawi (D), BS, Abdullah Ghali, BS, \\ Aws Alameri, MD (D), Mustafa Al Qaysi, MD (D) and Robert Nathanson, MD, FACP
}

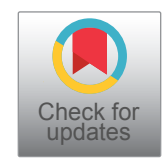

Department of Medicine, University of Texas Health Science Center, San Antonio, USA

*Corresponding author: Abdulrahman S Museedi, MD, Department of Medicine, University of Texas Health Science Center, 7703 Floyd Curl Drive, Mail Code 7870, San Antonio, TX 78229-3900, USA, Tel: 01-832-873-6249

\begin{abstract}
The burden of cardiovascular disease within the United States is profound, with large volumes of economic and academic resources being utilized to treat patients with cardiovascular diseases. Myocardial infarctions (MI) represent one of the most acute forms of cardiovascular pathology, with a profound mortality rate if prompt treatment and medical attention is not sought out after. While elements of changes in clinical practice and the spurring of new guidelines are responsible for improved health outcomes within year to year, the appraisal of trends in clinical outcomes allows for the scrutiny of methodology in approaching the patient with MI. Moreover, stratification of outcomes based on variables that have been shown to be associated with differential end outcomes in MI, such as age, sex, and type of institution allow for further partitioning of guidelines to meet more specific and tailored decision making guidelines or algorithms. For our dataset, a sampling of Ml discharges between the years of 2000 and 2015 using the National Inpatient Sample (NIS), an open-access all-player database that features data on inpatient statistics represented in hospital admissions within institutions that participate within the NIS. Analyses regarding year-to-year length of stay and mortality outcomes of patients by age, sex, and type of institution was performed, showing a decrease in MI discharges, and a statistically significant difference in mean length of stay time at teaching institutions vs. non-teaching hospitals. These results can be compared with contemporary guidelines to assess whether current clinical practice is equipped to address these differential clinical outcomes.
\end{abstract}

\section{Background}

Cardiovascular disease remains the leading cause of death in the United States, with myocardial infarctions representing an acute culmination of cardiovascular dis- ease. According to the American College of Cardiology, an American will have a myocardial infarction roughly every 40 seconds [1]. Despite this grave statistic, trends in myocardial infarction deaths in the United States have decreased markedly over roughly the past two decades, as can be appreciated by a query of Centers of Disease Control and prevention(CDC) Wonder for mentions of myocardial infarction using ICD-9 code entries on death certificates (Figure 1). CDC Wonder is a public health information systems platform that can be digitally accessed and hosts data regarding quantitative datapoints with qualitative features regarding death certificates within the United States [2]. Even more encouraging is not only the notion that myocardial infarction deaths have been trended downwards between 1999 and 2018, but the observation that myocardial deaths as a proportion of total deaths per 100,000 individuals has also decreased as can be appreciated by Figure 2 . However, myocardial infarction still represents a significant burden to the providers and institutions seeking to improve cardiovascular health outcomes amongst their populations. The economic impact of myocardial infarction has been estimated to be over $\$ 80$ billion annually by some studies [3]. Moreover, there is an increase in the volume of patient visits centered around the diagnosis, mitigation, or control of underlying risk factors for myocardial infarction, such as hypertension and Type 2 diabetes mellitus [4-6]. Long-term outcomes of survivors still pose prospective challenges to maintaining adequate cardiovascular health even if mortality is initially thwarted. Mortality may be seen in up to $10 \%$ 


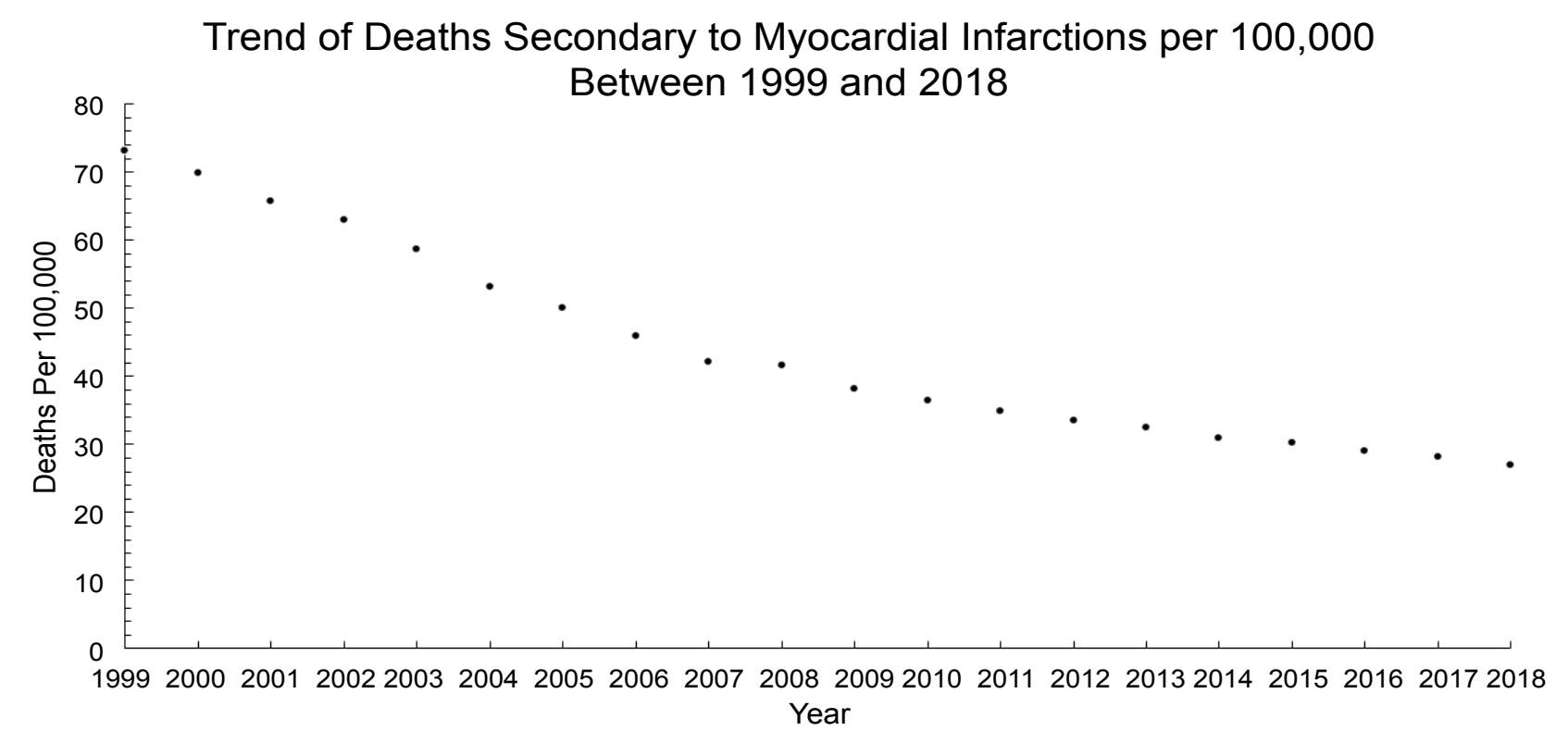

Figure 1: Age-adjusted deaths related to myocardial infarctions in the United States between 1999 and 2018.

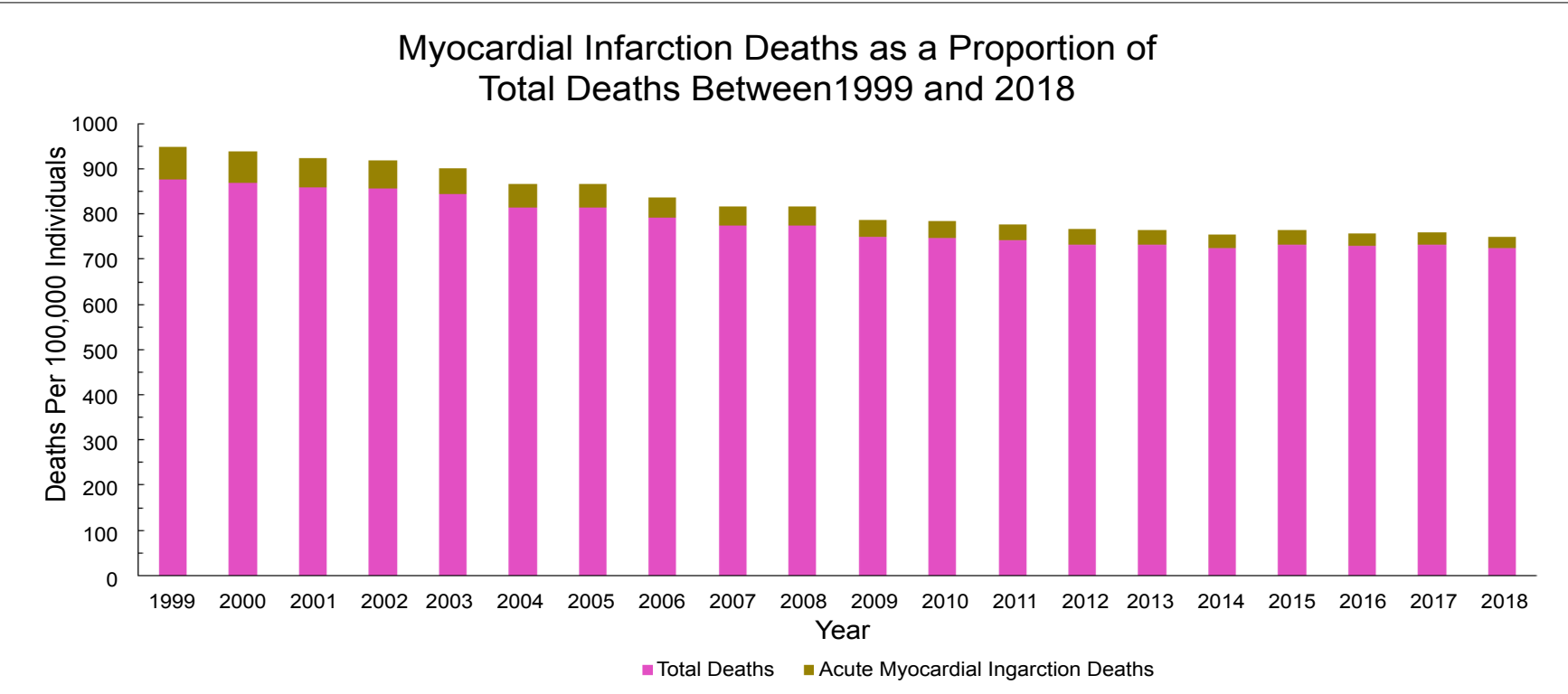

Figure 2: Age-Adjusted deaths related to myocardial infarctions as a proportion of total deaths in the United States between 1999 and 2018.

of survivors within the first year after an $\mathrm{MI}$, and up to one-half of all $\mathrm{MI}$ patients may experience rehospitalization within this same year time span [7]. To better improve institutional capacities regarding decision making in myocardial infarction encounters, it is prudent to assess the flux of patients with myocardial infarctions. Moreover, insight into discharge trends may help providers better understand the characteristics of patients undergoing discharge. The aim of this project is to assess the progress of the prevention and management of myocardial infarction by using the NIS data.

\section{Methods}

Data on myocardial infarction presentations to hospitalizations was assessed through a retrospective study utilizing The National Inpatient Sample (NIS) from 2000 through 2015. The NIS is a publicly available all-payer inpatient database that hosts data on hospital admissions for a wide array of clinical diagnoses and sequelae [8]. Myocardial infarction discharges from 2000 to 2015 were identified by using ICD-9 sorted by Clinical Classification Software (CCS). The rate of discharges per 100,000 persons, inpatient mortality, length of stay, and hospital cost were the variables trended. Inpatient mortality was further stratified by gender and by academic hospital status (teaching vs. non-teaching). Z-tests were implemented in order to elucidate statistical differences in the length of stay and mortality rate between teaching and non-teaching hospitals, as well as differences in the percentage of mortality between genders.

\section{Results}

The rate of myocardial infarction discharges per 


\section{Discharges Per 100,000 Between 2000 and 2015}

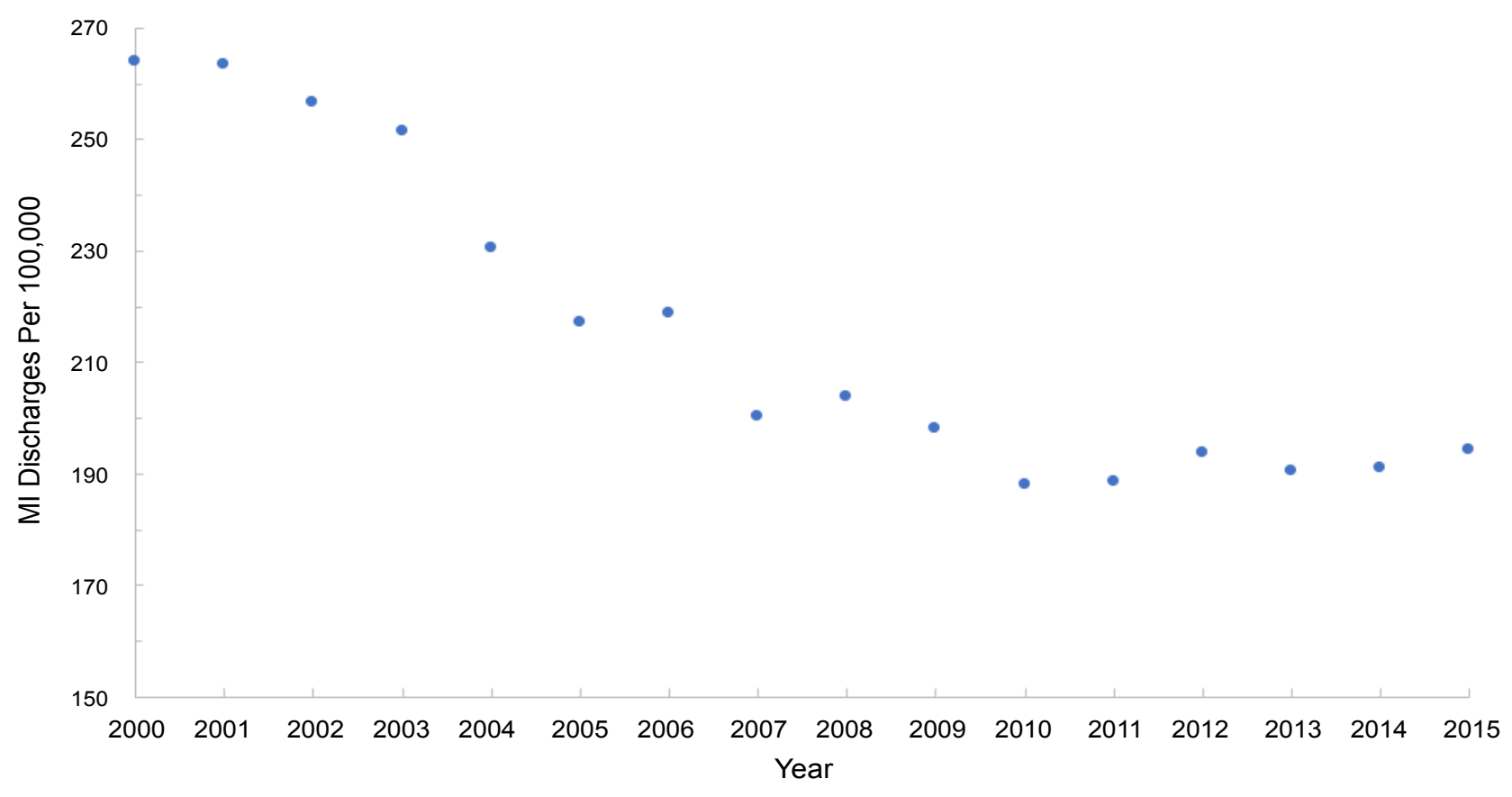

Figure 3: Myocardial infarction discharge rates per 100,000 individuals (aggregate) in the United States between 2000 and 2015.

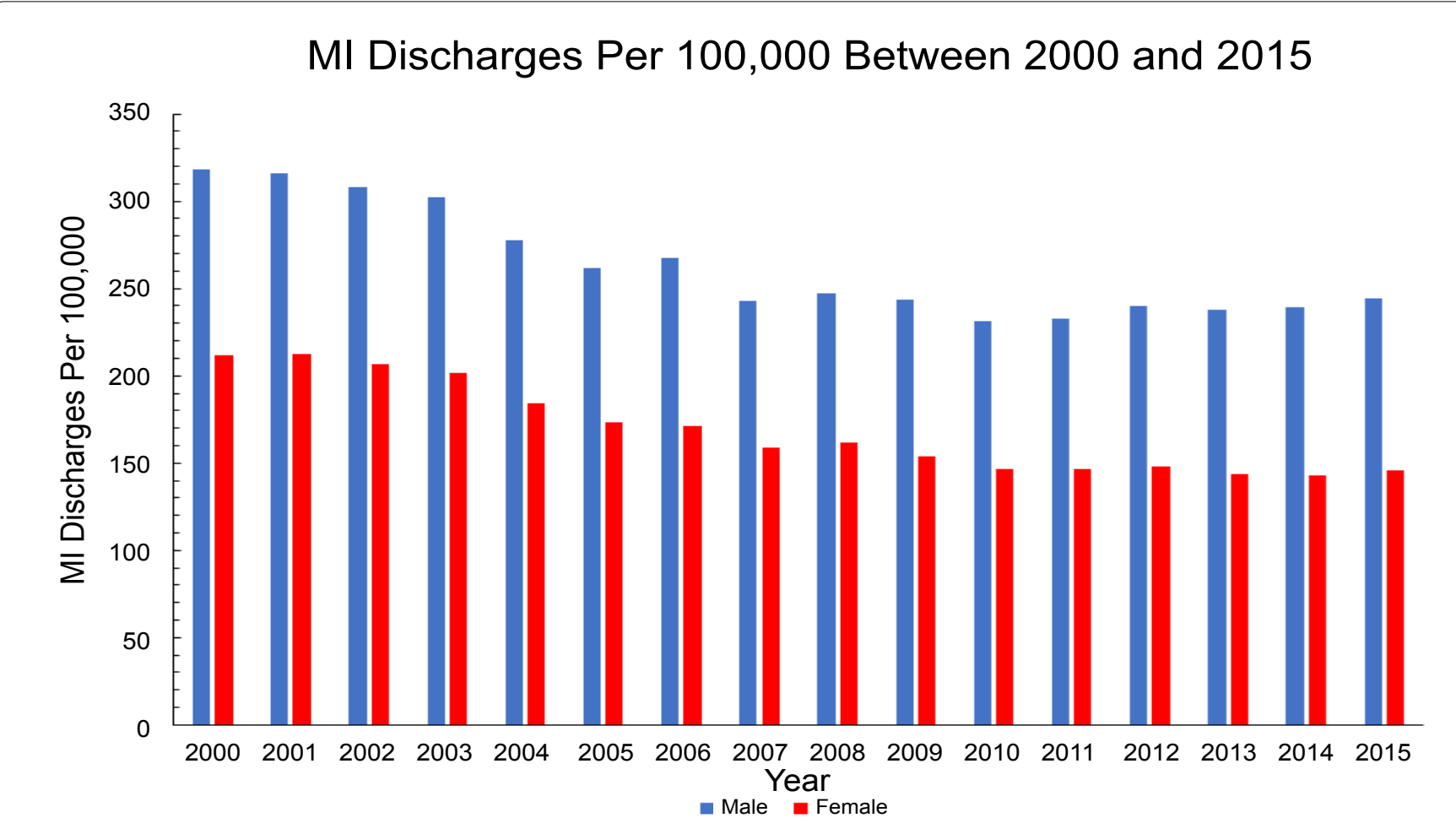

Figure 4: Myocardial infarction discharge rates per 100,000 individuals in the United States between 2000 and 2015 stratified by sex.

100,000 persons decreased in the years between 2000 and 2015 (Figure 3 and Figure 4). Similarly, inpatient mortality declined in both genders, but the female inpatient mortality rate was significantly higher over the 15 -year period ( $P$ value $<0.001$ ) (Figure 5 ). No change was noticed in the mean age for myocardial infarction of either gender over the studied time period (Figure 6). A visualization of the differences between genders and myocardial infarctions can be appreciated in Figure 4 . The rates of myocardial infarction for each gender markedly decreases as an overall trend within the time period, however no significant decreases can be appreciated between 2010 and 2015. A comparison of academic and non-academic institutions revealed no significant difference in inpatient mortality rate $(P$ value $>0.05$ ) (Figure 7). A statistically significant dif- 


\section{The percentage of $\mathrm{MI}$ inpatient mortality stratified by gender.}

12

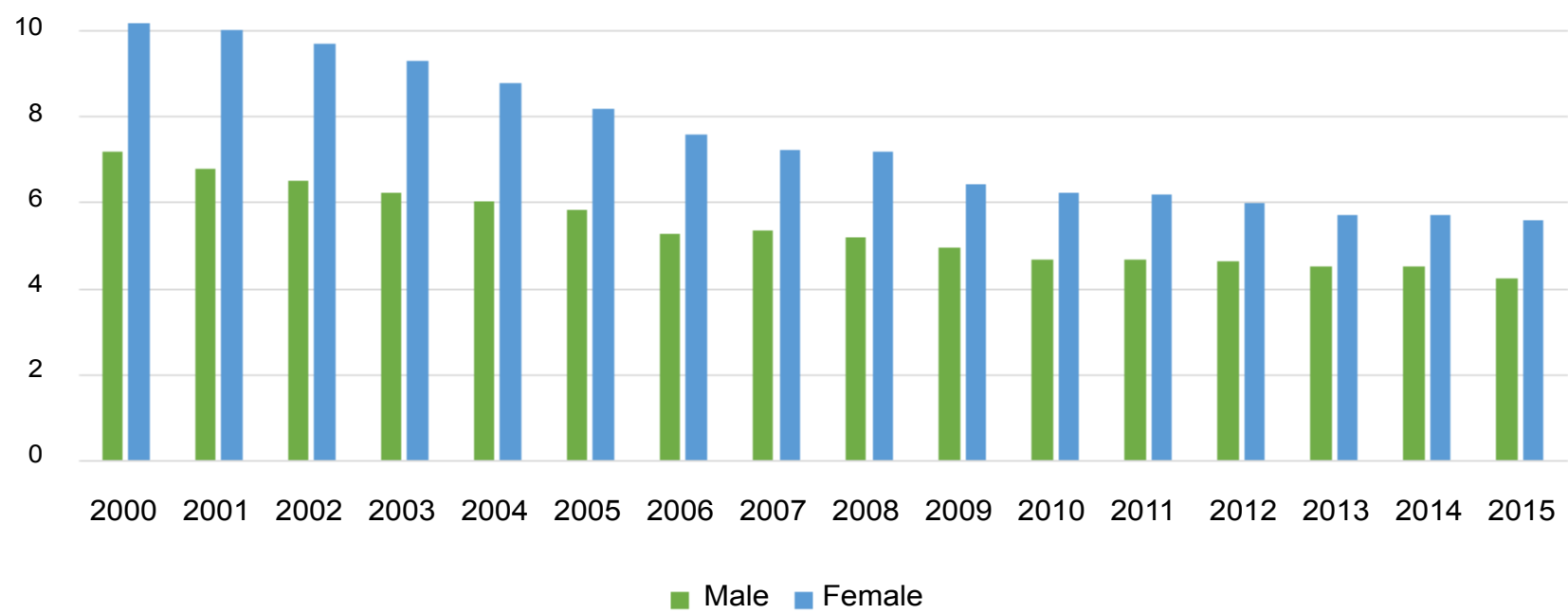

Figure 5: Percentage of myocardial infarction inpatient mortality stratified by gender $(P$ value $<0.001)$.

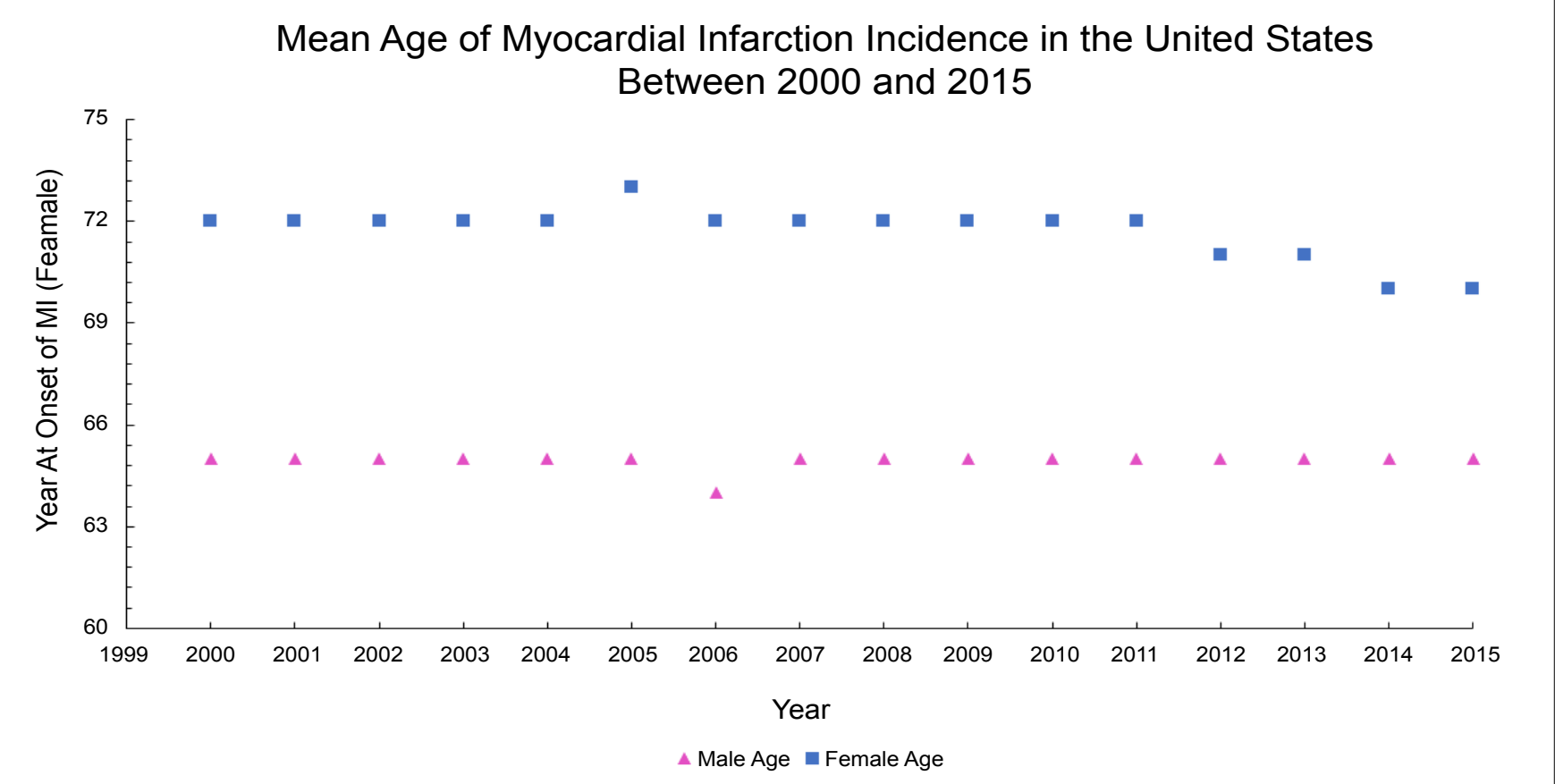

Figure 6: Differences in onset of myocardial infarction by age in the United States between 2000 and 2015.

ference in length of stay (P-value $<0.001)$ was noted when correlating differences in hospital cost (Figure 8 and Figure 9). The hospital cost has increased gradually overtime with teaching hospitals cost being higher than the non-teaching hospitals throughout the years of the study.

\section{Discussion}

The decrease in the rate of discharges reflects improvement in preventative measures and the role of primary and secondary prevention. Moreover, decreases in overall inpatient mortality secondary to myocardial infarctions is a testament to innovations in the medical and interventional management of myocardial infarction. However, this improvement in the management has led to a significant increase in hospital costs, and while may not rival the fiscal burden of death related to myocardial infarctions, it still represents an avenue for improvement in providing patients and institutions alike with long-term sustainability when fighting the battle against cardiovascular disease. The length of stay in teaching hospitals is longer than non-teaching hospitals per Figure 8, and the difference is statistically significant ( $P$ value $<0.001)$. However, there was no significant difference in inpatient mortality ( $\mathrm{P}$ value $>0.05$ ) (Figure 7 ). 


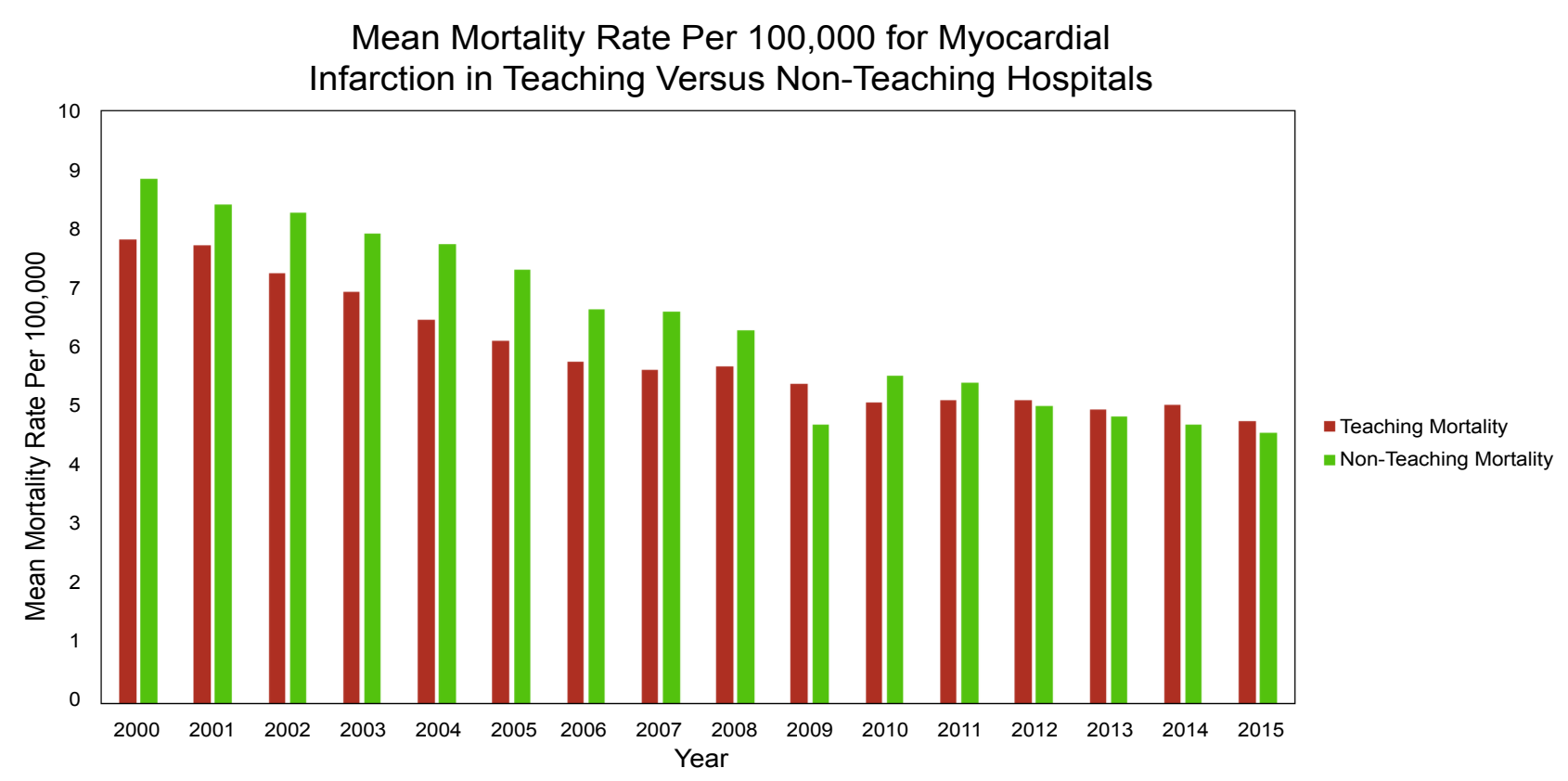

Figure 7: Myocardial infarction mortality per 100,000 individuals in the United States between 2000 and 2015 stratified by institutional setting $(P$ value $>0.05)$.

Mean Length of Stay for Myocardial Infarction in Teaching Versus Non- Teaching Hospitals

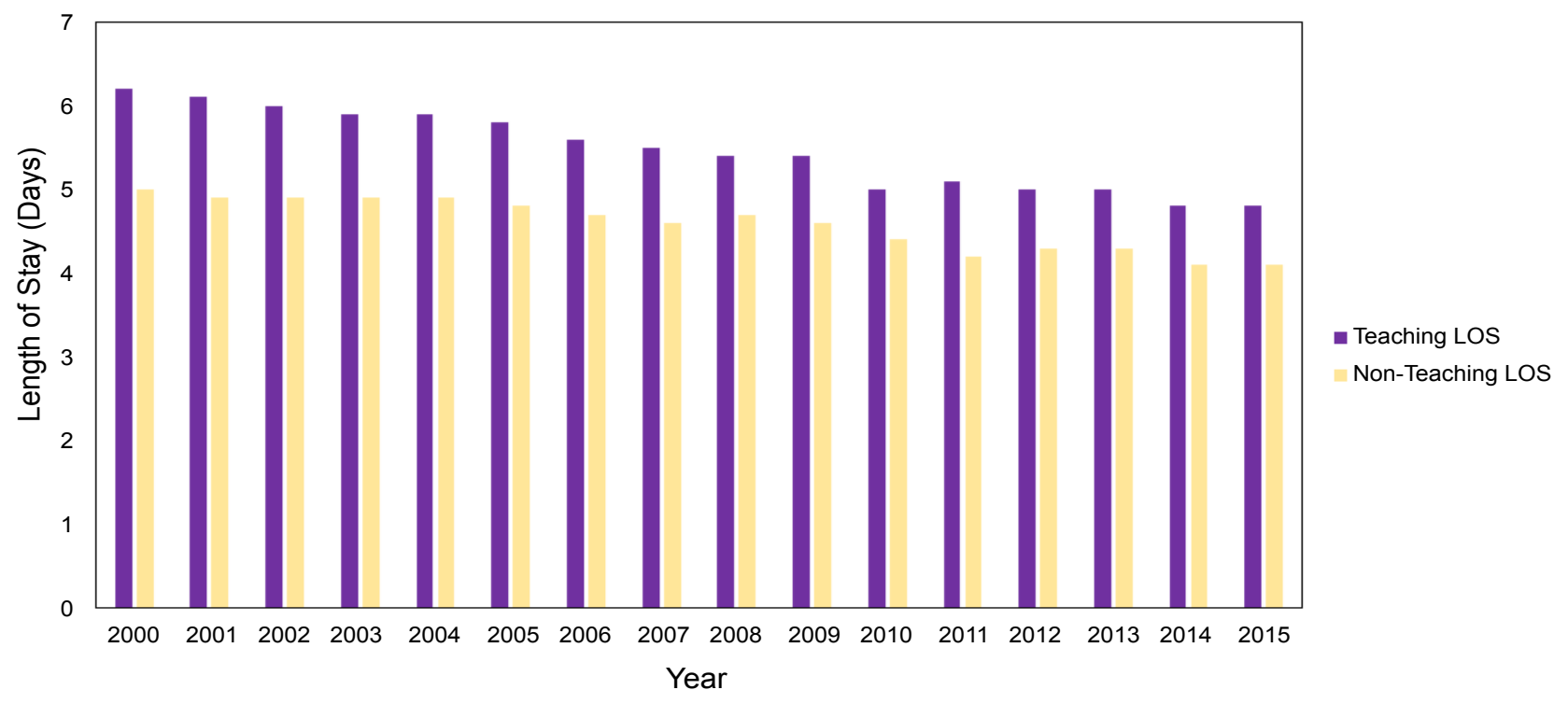

Figure 8: Myocardial infarction length of stay per 100,000 individuals in the United States between 2000 and 2015 stratified by institutional setting $(P$ value $<0.001)$.

Also, there is no change in the mean age for myocardial infarction for either gender throughout the course of this analysis interval, per Figure 6. Female sex status appears to be a non-modifiable risk factor for inpatient mortality. This is consistent with previous literature findings exhibiting a predilection for cardiovascular disease and sex secondary to differences in sex hormones and subsequent physiological differences as a result of these sex hormones which include, but are not limited to, increased hematocrit, lipid metabolism, and modifiability of vasculature [9-15]. While males generally have an increased risk for myocardial infarction and heart disease, studies show that delays in diagnoses are more prominent in women, especially in the setting of lack of chest pain in females presenting with $\mathrm{MI}$ that can delay in time to intervention, hence increasing female mortality than that of males. Besides, some studies noticed that the average age of women admitted with $\mathrm{Ml}$ is higher than that of men which can help explain higher female death rate $[16,17]$. The notion that women typically present with "atypical" MI symptoms has been recently challenged [18-20]. While this leads to downstream differential changes in hospital experience is yet to be fully elucidated. 


\section{Hospital cost in US Dollar}

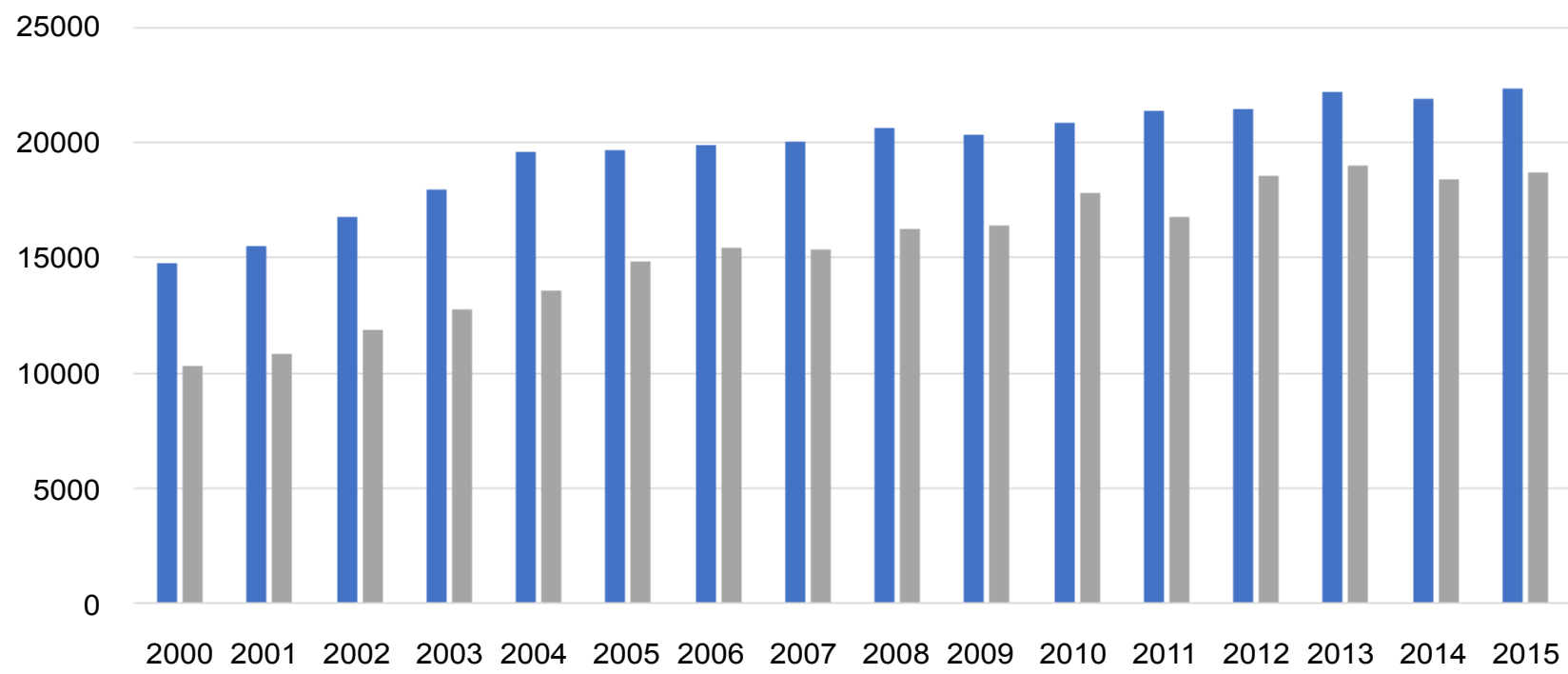

$$
\text { - Teaching Hospital } \quad \text { Non-Teaching Hospital }
$$

Figure 9: Trend of hospital cost per discharge comparing teaching and non-teaching hospitals.

\section{Conclusion}

In general, the results suggest a trend in more aggressive prevention, medical, and interventional management of myocardial infarction at the expense of increasing hospital costs. Additionally, our analyses may illustrate avenues for improvement at the institutional level in teaching hospitals in terms of reducing length of stay while maintaining similar outcomes in order to decrease hospital costs incurred, in an effort to match the costs of non-teaching hospitals. This phenomenon is also concerning in the context that previous analyses have demonstrated that academic institutions, while offering an increased amount of patient services, may be associated with higher readmission rate for myocardial infarctions [21]. Further goals may be applying the contemporary lessons learned from the NIS data trends in designating how each type of acute myocardial infarction affects patient outcomes and cost (e.g., STEMI vs. NSTEMI), as was done in a similar dataset spanning from 2001 to 2011 [22]. However, it is important to distinguish the populous of patients that arrive in teaching hospitals versus non-teaching hospitals to mitigate covariance that these patients may bring in the admission data for each respective type of institution.

\section{Conflict of Interest and Disclosures}

None.

\section{References}

1. Benjamin EJ, Muntner P, Alonso A, Bittencourt MS, Callaway CW, et al. (2019) Heart disease and stroke statistics-2019 update: A report from the American Heart Association. Circulation 139: e56-e528.

2. Friede A, Reid JA, Ory HW (1993) CDC WONDER: A comprehensive on-line public health information system of the
Centers for Disease Control and Prevention. Am J Public Health 83: 1289-1294.

3. Bishu KG, Lekoubou A, Kirkland E, Schumann SO, Schreiner A, et al. (2020) Estimating the economic burden of acute myocardial infarction in the US: 12 year national data. Am J Med Sci.

4. Buhnerkempe MG, Botchway A, Prakash V, Al-Akchar M, Nolasco Morales CE, et al. (2019) Prevalence of refractory hypertension in the United States from 1999 to 2014. J Hypertens 37: 1797-1804.

5. Shealy KM, Wu J, Waites J, Taylor NA, Blair Sarbacker G (2019) Patterns of diabetes screening and prediabetes treatment during office visits in the US. J Am Board Fam Med 32: 209-217.

6. Magliano DJ, Islam RM, Barr ELM, Gregg EW, Pavkov ME, et al. (2019) Trends in incidence of total or type 2 diabetes: Systematic review. BMJ 366: 15003.

7. Mechanic OJ, Grossman SA (2020) Acute Myocardial Infarction. Stat Pearls.

8. Houchens RL, Ross DN, Elixhauser A, Jiang J (2014) Nationwide inpatient sample redesign final report. 2014. HCUP NIS Related Reports ONLINE. U.S. Agency for Healthcare Research and Quality.

9. Anderson RD, Pepine CJ (2007) Gender differences in the treatment for acute myocardial infarction. Circulation 115: 823-826.

10. Grosman H, Rosales M, Fabre B, Nolazco C, Mazza O, et al. (2014) Association between testosterone levels and the metabolic syndrome in adult men. Aging Male 17: 161-165.

11. Konig CS, Balabani S, Hackett GI, Strange RC, Ramachandran S (2019) Testosterone therapy: An assessment of the clinical consequences of changes in hematocrit and blood flow characteristics. Sex Med Rev 7: 650-660.

12. Ghosh M, Galman C, Rudling M, Angelin B (2015) Influence of physiological changes in endogenous estrogen on circulating PCSK9 and LDL cholesterol. J Lipid Res 56: 463-469. 
13. White RJ (2016) Estrogen: Friend or foe in pulmonary hypertension? Am J Respir Crit Care Med 193: 1084-1086.

14. Choi BG, McLaughlin MA (2007) Why men's hearts break: Cardiovascular effects of sex steroids. Endocrinol Metab Clin North Am 36: 365-377.

15. Ziemens B, Wallaschofski H, Volzke H, Rettig R, Dörr M, et al. (2013) Positive association between testosterone, blood pressure, and hypertension in women: Longitudinal findings from the Study of Health in Pomerania. J Hypertens 31: 1106-1113.

16. Mehta LS, Beckie TM, DeVon HA, Grines CL, Krumholz $\mathrm{HM}$, et al. (2016) Acute myocardial infarction in women. Circulation 133: 916-947.

17. Muhrbeck J, Maliniak E, Eurenius L, Hofman-Bang C, Persson J (2020) Few with ST-segment elevation myocardial infarction are diagnosed within 10 minutes from first medical contact, and women have longer delay times than men. Int J Cardiol Heart Vasc 26: 100458.

18. Albarran JW, Clarke BA, Crawford J (2007) 'It was not chest pain really, I can't explain it!' An exploratory study on the nature of symptoms experienced by women during their myocardial infarction. J Clin Nurs 16: 1292-1301.

19. Canto JG, Goldberg RJ, Hand MM, Bonow RO, Sopko G, et al. (2007) Symptom presentation of women with acute coronary syndromes: Myth vs reality. Arch Intern Med 167: 2405-2413.

20. Ferry AV, Anand A, Strachan FE, Mooney L, Stewart SD, et al. (2019) Presenting symptoms in men and women diagnosed with myocardial infarction using sex-specific criteria. J Am Heart Assoc 8: e012307.

21. Shahian DM, Nordberg P, Meyer GS, Blanchfield BB, Mort EA, et al. (2012) Contemporary performance of US teaching and nonteaching hospitals. Acad Med 87: 701-708.

22. Sugiyama T, Hasegawa K, Kobayashi Y, Takahashi O, Fukui T, et al. (2015) Differential time trends of outcomes and costs of care for acute myocardial infarction hospitalizations by ST elevation and type of intervention in the United States, 2001-2011. J Am Heart Assoc 4: e001445. 